\title{
Reduction of Cerebrospinal Fluid Phenylalanine after Oral Administration of Valine, Isoleucine, and Leucine
}

\author{
HELEN K. BERRY, ${ }^{(3 i)}$ MARY K. BOFINGER, MELANIE M. HUNT, PAMELA J. PHILLIPS, \\ MARY B. GUILFOILE \\ Institute for Developmental Research of the Children's Hospital Research Foundation and the Department of \\ Pediatrics, The University of Cincinnati College of Medicine, Cincinnati, Ohio, USA
}

\begin{abstract}
Summary
A supplement of the branched chain amino acids, valine, isoleucine, and leucine (VIL) was administered orally to patients with phenylketonuria, either together with unrestricted diet of natural protein or with a low phenylalanine diet. The VIL supplement brought about a significant reduction of the cerebrospinal fluidserum ratio of phenylalanine from a mean value of 0.254 without VIL to 0.204 with VIL. The reduction varied from $15-40 \%$ (mean 21\%). Concentrations of glycine, lysine, methionine, threonine, tryptophan, and tyrosine were within normal limits in serum and cerebrospinal fluid of infants with phenylketonuria. No amino acid imbalance was created by the supplement and no adverse effects from VIL were observed.
\end{abstract}

\section{Speculation}

The branched chain amino acids and phenylalanine share a common transport system. High levels of phenylalanine in brain of children with phenylketonuria may be reduced by administration of a supplement of valine, isoleucine and leucine (VIL). Supplementation of the low-phenylalanine diet with VIL during the first 2 years of life may add a measure of protection to the developing brain beyond that which can be achieved by diet alone. In older children, VIL supplementation may permit liberalization of the diet without unfavorable behavioral consequences.

Treatment for phenylketonuria (PKU) by means of a lowphenylalanine diet has become common practice since its first use in affected newborn infants (3). The treatment partially corrects the abnormal amino acid pattern, including the high concentration of phenylalanine and its metabolites, and allows relatively normal intellectual and physical development if the treatment is begun early enough (10). Initially it was assumed that treatment would be terminated when major phases of brain growth were completed. Evidence has accumulated which suggests that termination of treatment for the patient with classic PKU, at least during the school years, is unwise $(13,15,16)$ and it may be prudent to continue the diet into adult years for women with PKU in order to avoid the teratogenic effects of phenylalanine (6).

An animal model developed in this laboratory was used to demonstrate the effects of experimental hyperphenylalaninemia (PKU) (12). Methods to inhibit the deleterious effects of phenylalanine on the central nervous system were studied in the model. Administration of branched chain amino acids, valine, isoleucine, and leucine (VIL), to pregnant rats with experimentally induced PKU prevented the decrease in fetal brain weight characteristic of PKU animals (7). A striking finding was that phenylalanine levels in brain of PKU fetuses whose mothers received VIL supplement were lower than in PKU fetuses not exposed to VIL, although fetal blood phenylalanine levels were similar. Subsequent studies suggested that isoleucine was more effective than other amino acids in exerting a beneficial effect on fetal rat brain growth (11).

Human trials followed. VIL was first used as a supplement to the low-phenylalanine diet of several older PKU children in whom there were behavioral or neurologic changes, which might be used as indicators of the effect of an alternate treatment. Improvement in neuropsychologic functioning was seen during periods of VIL supplementation, whereas no changes occurred during alternate periods without VIL (7). We also reported data indicating that, in the presence of VIL, levels of phenylalanine in cerebrospinal fluid (CSF) were reduced $15-30 \%$ without a corresponding decrease in serum phenylalanine levels $(8,9)$. The purpose of this paper is to report in more detail the effect of VIL on amino acid concentrations in CSF and serum of children with PKU, and to demonstrate its safety.

\section{MATERIALS AND METHODS}

Administration of VIL. L-Valine, L-isoleucine and L-leucine (Ajinomoto USA, Inc., N.Y., N.Y.) in crystalline form was used. VIL was suspended in water and taken orally by older PKU children not on diet. Flavorings were used by some to mask the bitter taste. The suspended VIL was blended with the low-phenylalanine formula for children on diet. VIL was dissolved in water by boiling and added directly either to milk formula or to low-phenylalanine formula for infants.

Subjects. Subjects were untreated and treated PKU patients ranging in age from 11 days to 22 years. With one exception (Patient 8), all had serum phenylalanine concentrations of $35 \mathrm{mg} /$ $\mathrm{dl}$ or greater at the time of initial diagnosis. They are described in more detail below.

Treatment with VIL. A 22-year-old retarded woman with PKU (Patient 1) was admitted to the hospital for evaluation of nocturnal vomiting and night terrors. She was treated in our clinic for approximately 9 years from age $3-12$, but had been on an unrestricted diet for approximately 10 years at the time of the study. Blood and CSF for amino acid measurements were collected after an overnight fast. A supplement of valine $(150 \mathrm{mg} / \mathrm{kg})$, isoleucine $(150 \mathrm{mg} / \mathrm{kg})$, and leucine $(200 \mathrm{mg} / \mathrm{kg})$ was divided into 4 equal doses and given at meals and at bedtime. No other changes were made in her diet. Daily protein intake was $75-90 \mathrm{~g}$. On the first day of treatment blood was collected at frequent intervals for amino acid measurements. After $48 \mathrm{~h}$ of VIL treatment, after an overnight fast, blood and CSF samples were again obtained.

Three early-treated PKU children ages 7, 10, and 12 years, not currently receiving treatment, were given VIL for 6 wk before reinstatement of a low-phenylalanine diet (Patients 2, 3, 4). The mother was concerned because of aggressive behavior and extreme irritability in the youngest child and, in the 10-year-old, a decline in measured IQ from 95 to 75 since termination of the diet at age 5 years. Blood and CSF were collected before administration of VIL and at the end of the 6-wk period while still on an unrestricted 
diet. The daily VIL dosage was the same as used for patient 1 . At the end of VIL treatment all three children were placed on a lowphenylalanine diet.

Six infants were referred to our clinic since January, 1978, five because of a positive test for phenylalanine on newborn screening (Patients 5-7, 9, 10). Another infant (Patient 8) was born into a family in which an older child had a variant form of PKU. After confirmation of serum phenylalanine levels above $20 \mathrm{mg} / \mathrm{dl}$, at ages ranging from 11-17 days the infants were hospitalized for VIL trials and treatment with low-phenylalanine diet. CSF and blood were obtained before any treatment. A supplement of valine $(135 \mathrm{mg} / \mathrm{kg})$, isoleucine $(129 \mathrm{mg} / \mathrm{kg})$, and leucine $(241 \mathrm{mg} / \mathrm{kg})$ was then added to the infant's formula. The dosage of VIL for infants was based on the content of these amino acids in breast milk and was calculated to double the recommended intake. After $48 \mathrm{~h}$ of VIL exposure, CSF and blood were again collected and treatment with low-phenylalanine formula was begun. One infant (Patient 5) was given VIL only during the 48-h period while still on natural protein and before beginning low-phenylalanine formula. For three infants VIL was added to the low-phenylalanine formula for 4-wk periods followed by 4-wk periods without VIL (patients $6,7,8$ ). When no adverse effects of VIL were noted after these short periods, VIL treatment was continued without interruption. Patients 9 and 10 began VIL treatment at the time the low phenylalanine diet was introduced and remained on the supplement.

The parents of Patient 11 requested a trial of VIL as a supplement to the low-phenylalanine diet for their son in whom dietary control was often erratic. Blood and CSF were collected before and after $48 \mathrm{~h}$ of VIL administration. The dosage was the same as for Patient 1. VIL treatment was then continued along with the low-phenylalanine diet.

Amino acid measurements. Immediately after collection, blood was centrifuged in the cold and deproteinized with an equal volume of $20 \%$ sulfosalicylic acid. CSF was deproteinized by addition of $100 \mathrm{mg}$ sulfosalicylic acid to $0.5 \mathrm{ml} \mathrm{CSF}$. Norleucine was added as internal standard to both. Amino acids in the protein free supernatants were measured on a Beckman Model 119B Amino Acid Analyzer.

\section{RESULTS}

Table 1 shows the effect of supplementing the regular diet with VIL on concentrations of phenylalanine, tyrosine, and the branched chain amino acids in Patient 1. Phenylalanine concentrations were surprisingly constant during the period in spite of intervening meals. Changes in tyrosine concentrations were inconsistent and were not related to increased concentration of phe- nylalanine or branched chain amino acids. Concentrations of the branched chain amino acids were below normal in a fasting specimen. Concentrations of all three amino acids rose 4-8-fold within $30 \mathrm{~min}$ of the first dose (one-quarter of daily supplement) and declined to about twice normal by the time of the next meal. After the second dose, peak levels of branched chain amino acids were only 3-4 times fasting concentrations. No alloisoleucine was detected. This isomer might be expected to occur if the capacity for metabolism of isoleucine were exceeded.

Data shown in Table 2 are representative of the amino acid concentrations in CSF and serum in both untreated and treated PKU patients before and after VIL administration. Changes in serum phenylalanine concentrations were relatively small $(1-8 \%)$ except for Patient 4, whereas the decrease in CSF phenylalanine was $15-40 \%$. The largest decrease in CSF phenylalanine, $40 \%$ in Patient 4 , was accompanied by $18 \%$ decrease in serum phenylalanine concentration. After VIL administration, tyrosine concentrations decreased in both CSF and serum of patients not on dietary treatment, but increased slightly in patients on diet. Fasting levels of branched chain amino acids in Patient 1 were below normal before supplementation and remained below normal. Postprandial levels were measured in the other patients to observe the maximum effect of the VIL supplement on amino acid concentrations. In most instances branched chain amino acids were normal or only slightly below normal in nonfasting CSF and serum before the study. After VIL treatment branched chain amino acid levels increased both in CSF and serum.

The relation of phenylalanine in CSF to that in serum of PKU patients before and after VIL treatment is shown in Figure 1. For given levels of phenylalanine in serum, concentrations of phenylalanine in CSF were lower in the presence of VIL. As expected, CSF and serum phenylalanine concentrations were highly correlated. A linear relation was apparent up to serum phenylalanine concentrations of about $2000 \mu$ moles/liter. The ratio of phenylalanine in CSF to serum for each patient before and after VIL treatment is shown in Figure 2. In Patients 9 and 10 the post-VIL CSF specimens were lost. The protocol did not permit repeating the spinal taps. VIL treatment consistently reduced the CSF-serum ratio of pnenylalanine. The mean value of $0.254+0.044$ without VIL was significantly greater than the mean of $0.204 \pm 0.043$ with VIL $(P<0.004$, Sign Test) $(23)$.

Table 3 shows the effect of VIL on CSF and serum levels of amino acids representing several amino acid transport systems and the aromatic amino acids. Before administration of VIL, the branched chain amino acids were within normal range in serum of PKU infants either while fed unrestricted diet with natural protein or after introduction of low-phenylalanine formula. Serum levels of branched chain amino acids were raised more than $100 \%$

Table 1. Effect of valine, isoleucine, and leucine (VIL) supplement at mealtime on serum amino acids ${ }^{1}$ of patient 1

\begin{tabular}{|c|c|c|c|c|c|c|}
\hline & $\begin{array}{c}\text { Time after } \\
\text { meal with } \\
\text { VIL supplement }\end{array}$ & Phenylalanine & Tyrosine & Valine & Isoleucine & Leucine \\
\hline & Fasting & 1579 & 51 & 169 & 50 & 88 \\
\hline \multirow[t]{4}{*}{ After breakfast } & $30 \mathrm{~min}$ & 1623 & 47 & 552 & 396 & 460 \\
\hline & $1 \mathrm{~h}$ & 1670 & 47 & 476 & 294 & 443 \\
\hline & $2 \mathrm{~h}$ & 1779 & 46 & 358 & 125 & 202 \\
\hline & $3 \mathrm{~h}$ & 1741 & 54 & 321 & 102 & 168 \\
\hline \multirow{5}{*}{ After lunch } & $30 \mathrm{~min}$ & 1724 & 48 & 357 & 121 & 177 \\
\hline & $1 \mathrm{~h}$ & 1647 & 43 & 311 & 119 & 175 \\
\hline & $2 \mathrm{~h}$ & 1655 & 43 & 480 & 232 & 368 \\
\hline & $3 \mathrm{~h}$ & 1691 & 40 & 429 & 145 & 230 \\
\hline & $4 \mathrm{~h}$ & 1623 & 37 & 294 & 73 & 121 \\
\hline \multirow[t]{2}{*}{ After dinner } & $30 \mathrm{~min}$ & 1647 & 48 & 427 & 141 & 179 \\
\hline & $1 \mathrm{~h}$ & 1623 & 48 & 442 & 161 & 210 \\
\hline \multicolumn{7}{|l|}{ Normal women ${ }^{2}$} \\
\hline Mean & & 56 & 61 & 209 & 64 & 122 \\
\hline S.D. & & 8 & 13 & 31 & 13 & 23 \\
\hline
\end{tabular}

\footnotetext{
${ }^{1}$ Amino acid concentrations are expressed as $\mu$ moles/liter.
}

${ }^{2}$ See reference number 4 . 
Table 2. Amino acid concentrations ${ }^{1}$ in cerebrospinal fluid (CSF) and serum before and after supplementation with valine, isoleucine, and leucine (VIL)

\begin{tabular}{|c|c|c|c|c|c|c|c|c|c|c|}
\hline & \multicolumn{2}{|c|}{ Phenylalanine } & \multicolumn{2}{|c|}{ Tyrosine } & \multicolumn{2}{|c|}{ Valine } & \multicolumn{2}{|c|}{ Isoleucine } & \multicolumn{2}{|c|}{ Leucine } \\
\hline & $\mathrm{CSF}$ & Serum & $\mathrm{CSF}$ & Serum & $\mathrm{CSF}$ & Serum & $\mathrm{CSF}$ & Serum & CSF & Serum \\
\hline \multicolumn{11}{|l|}{ Patient 1} \\
\hline - VIL & 527 & 2059 & 16 & 57 & 3 & 161 & 1 & 44 & 5 & 71 \\
\hline+ VIL & 365 & 2007 & 9 & 30 & 5 & 152 & 3 & 58 & 7 & 88 \\
\hline \multicolumn{11}{|l|}{ Patient 2} \\
\hline- VIL & 520 & 1862 & 15 & 47 & 11 & 204 & 4 & 47 & 9 & 109 \\
\hline+ VIL & 355 & 1820 & 9 & 29 & 27 & 290 & 6 & 58 & 13 & 99 \\
\hline \multicolumn{11}{|l|}{ Patient 3} \\
\hline- VIL & 414 & 1808 & 15 & 50 & 11 & 227 & 4 & 50 & 8 & 103 \\
\hline+ VIL & 352 & 1790 & 8 & 29 & 29 & 431 & 8 & 101 & 19 & 171 \\
\hline \multicolumn{11}{|l|}{ Patient 4} \\
\hline - VIL & 456 & 1825 & 13 & 38 & 19 & 190 & 2 & 33 & 6 & 92 \\
\hline+ VIL & 273 & 1510 & 7 & 35 & 29 & 448 & 10 & 102 & 22 & 173 \\
\hline \multicolumn{11}{|l|}{ Patient 6} \\
\hline- VIL & 56 & 277 & 6 & 27 & 12 & 192 & 5 & 51 & 10 & 91 \\
\hline+ VIL & 42 & 254 & 8 & 49 & 20 & 320 & 5 & 61 & 14 & 125 \\
\hline \multicolumn{11}{|l|}{ Patient 11} \\
\hline - VIL & 154 & 694 & 7 & 34 & 17 & 205 & 4 & 41 & 10 & 70 \\
\hline+ VIL & 103 & 659 & 8 & 45 & 28 & 558 & 10 & 148 & 24 & 214 \\
\hline \multicolumn{11}{|c|}{ Normal Children $^{2}$} \\
\hline (6-18 years) & 9 & 58 & 10 & 67 & 11 & 223 & 4 & 67 & 10 & 127 \\
\hline
\end{tabular}

${ }^{1}$ Amino acid concentrations are expressed as $\mu$ moles/liter. Normal values for CSF are from 20 infants and children studied in this laboratory. Patients 1-4 were on unrestricted diets; patients 6 and 11 were on low phenylalanine diets. Specimens were obtained from Patient 1 while fasting. All other specimens were collected approximately $2 \mathrm{~h}$ after a meal. Period of VIL administration was $48 \mathrm{~h}$ for Patients 1 and 6,4 wk for Patient 6 and 6 wk for Patients 2, 3, and 4.

${ }^{2}$ See references number 4 .

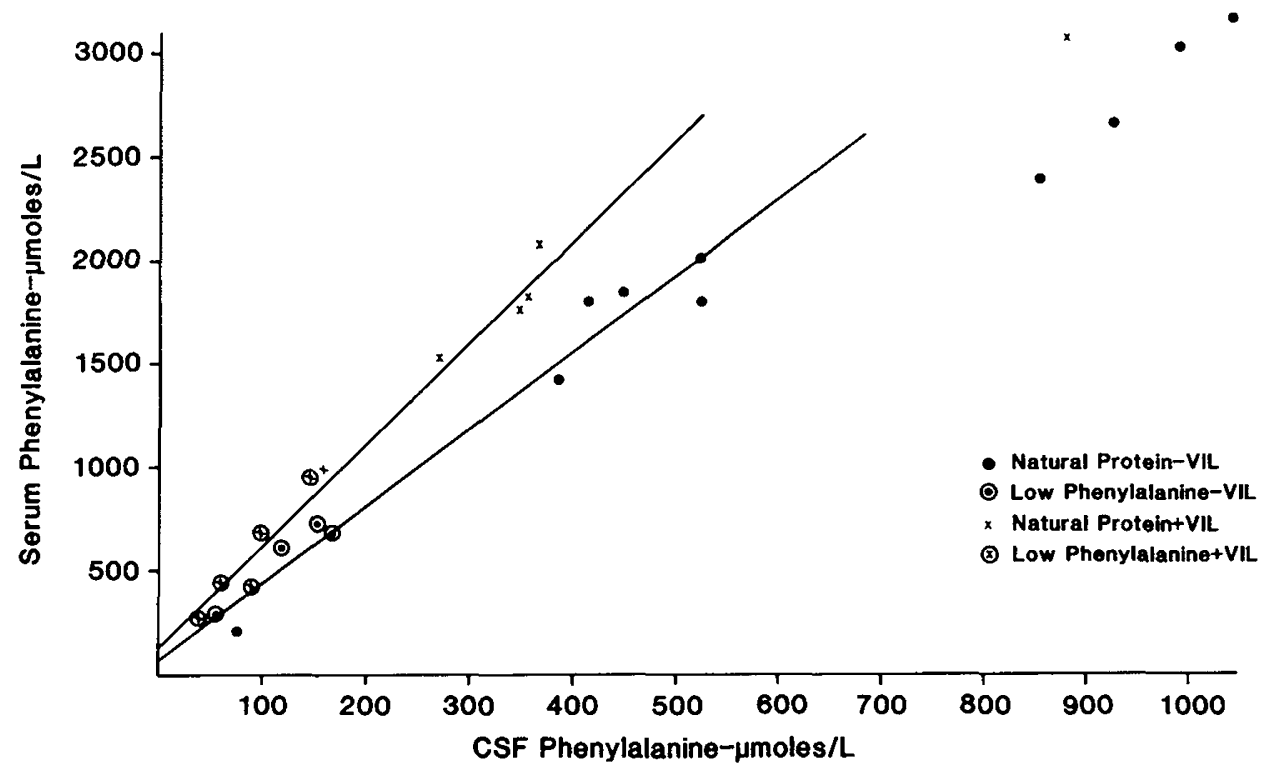

Fig. 1. Cerebrospinal fluid (CSF) and serum levels of phenylalanine in phenylketonuria (PKU) patients on regular diet or low-phenylalanine diet with and without valine, isoleucine, and leucine (VIL) supplementation.

after $48 \mathrm{~h}$ of VIL, compared to pretreatment levels, but were only about $50 \%$ higher after 4 wk of VIL treatment. Branched chain amino acids in CSF of PKU infants were above normal before treatment with VIL or with low-phenylalanine diet, and levels were raised about $50 \%$ following VIL. Concentrations of glycine, lysine, methionine, threonine, and tryptophan were within the normal range in serum and CSF. Values before and after VIL treatment were not significantly different from those of non-PKU infants. Tyrosine levels in both CSF and serum were at the upper limit of normal in untreated PKU infants. Tyrosine in serum increased after $48 \mathrm{~h}$ of VIL treatment, but CSF tyrosine was not significantly altered. Tyrosine concentration was unaffected by 4 wk of VIL treatment. Mean serum phenylalanine concentrations were about $23 \%$ lower after administration of VIL whereas mean CSF levels were decreased by $40 \%$. The magnitude of the decline in CSF phenylalanine was similar whether infants were on diets restricted or unrestricted in phenylalanine.

\section{DISCUSSION}

Our observations of normal or even slightly raised values for large neutral amino acids in serum and CSF from infants with PKU before introduction of the low-phenylalanine diet are similar to those of Snyderman, et al. (24). They found similar levels in CSF for the same amino acids with the exception of threonine, which was lower in PKU than in normal infants. Our value for 
CSF threonine was similar to theirs, but our normal value of 35 $\mu$ moles/liter was lower than their value of $53 \mu$ moles/liter. Neither we nor Snyderman et al. (24) found evidence for tyrosine deficiency in CSF of infants with PKU. Older untreated PKU patients in our study showed the depression in large neutral amino acids reported by other investigators (20). The depression in plasma and CSF amino acids may develop slowly over time in the presence of chronic high levels of circulating phenylalanine. Early treatment with low-phenylalanine diet may inhibit the depressing effect of phenylalanine on other amino acids coincident with the prevention of brain damage.

The underlying biochemical defect leading to mental retardation in PKU is still unknown. A theory supported by a substantial amount of experimental evidence is that overloading of a common carrier system for large neutral amino acids by excess phenylalanine interferes with transport of other essential amino acids into brain $(5,20,21,27)$. The decreased availability of amino acids leads to depressed protein and lipoprotein synthesis both in vivo and in vitro $(1,5,14,19,22,25,26)$. The actual inhibition of protein synthesis by excess phenylalanine is about $20 \%$ (17). Several investigators have suggested administration of other large neutral amino acids as an experimental therapeutic approach to PKU (2, 18). Hughes and Johnson (18) reported reversal of phenylalanine-induced disaggregation of brain polyribosomes by injection of a mixture of large neutral amino acids. Anderson and Avins (2) showed, in hyperphenylalaninemic rats, that increasing serum levels of amino acids, which compete with phenylalanine

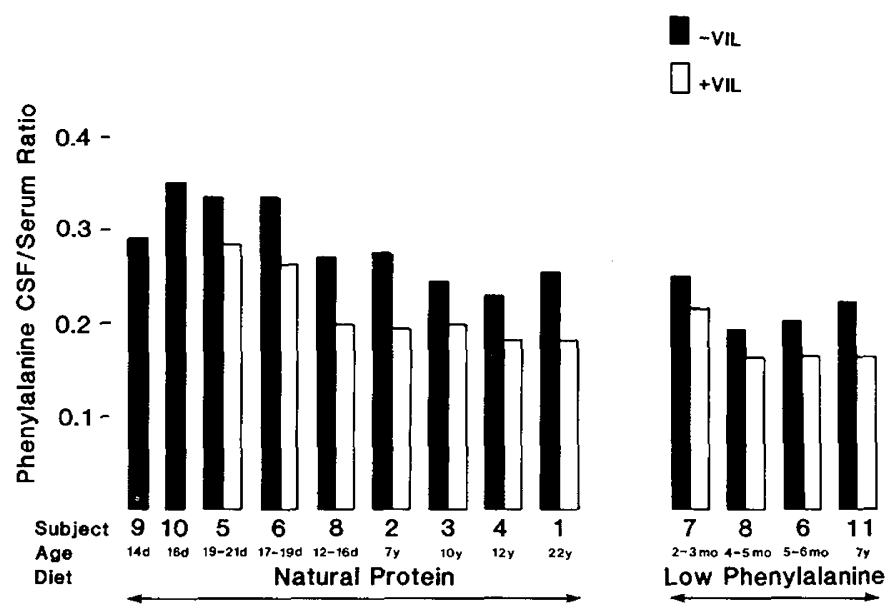

Fig. 2. Cerebrospinal fluid (CSF)-serum ratio of phenylalanine in phenylketonuria (PKU) patients before and after valine, isoleucine, and leucine (VIL) supplementation of natural protein or low-phenylalanine diet. for transport across the blood brain barrier, lowered brain phenylalanine levels and the brain-serum phenylalanine ratio.

The present approach extends the above findings to children with PKU. The objective of this study was to lower brain phenylalanine in PKU patients by dietary administration of branched chain amino acids. Our objective was achieved in that VIL treatment reduced the phenylalanine concentration in CSF beyond that which could be obtained by dietary phenylalanine restriction alone. We are encouraged to continue the study by reports of use of branched chain amino acids for treatment of patients with hepatic and renal disease, inflammation, diabetes, sepsis, and trauma (28). No adverse effects from VIL were observed in our patients, some of whom have been on VIL supplement for 2 years. Blood glucose levels were normal and alloisoleucine was never detected. Branched chain keto acids were not detected in urine. No amino acid imbalance was created, judging by the fact that concentrations of other amino acids, including tyrosine and tryptophan, were not depressed by VIL.

Inability to achieve optimum control of serum phenylalanine levels early in life is probably the chief factor contributing to the intellectual deficits now seen in many early treated children when they are compared to unaffected family members (10). We have observed a significant negative correlation between serum phenylalanine levels measured at 1-2 years of life and IQ measured at ages of 4-16 years. The first 2 years of life, during which brain protein synthesis is greatest, are the most critical in treatment of PKU. Supplementation of the low phenylalanine diet with VIL during this critical period in infancy may add a measure of protection to the developing brain beyond that which can be achieved by diet alone. In older children VIL supplementation may permit liberalization of the diet without unfavorable behavioral consequences. A series of studies are in progress in older PKU children to observe the effects of VIL on behavior, attention span and short term memory.

\section{REFERENCES AND NOTES}

1. Agrawal, H. C., Bone, A. H., and Davison, A. N.: Effect of phenylalanine on protein synthesis in the developing rat brain. Biochem. J., 117: 325 (1970).

2. Andersen, A. E. and Avins, L.: Lowering brain phenylalanine levels by giving other large neutral amino acids. Archs. Neurol., 33: 634 (1976).

3. Armstrong, M. D. and Binkley, E. L. Jr.: Studies on phenylketonuria. V. Observations on a newborn infant with phenylketonuria. Proc. Soc. Exper. Biol. Med., 93: 481 (1956).

4. Armstrong, M. D. and Stave, U.: A study of plasma free amino acid levels. II Normal values for children and adults. Metabolism, 22: 561 (1973).

5. Berger, R., Dias, T., and Hommes, F. A.: Developmental aspects of brain protein and myelin metabolism in hyperphenylalaninemic rats. In: F. A. Hommes, Ed. Models for the study of inborn errors of metabolism, pp 111-121. (Elsevier North Holland, Biomedical Press, Amsterdam, 1979).

6. Berry, H. K.: Hyperphenylalaninemias and tyrosinemias. Clin. Perinatol., 3: 15 (1976).

7. Berry, H. K., Butcher, R. E., Brunner, R. L., Bray, N. W., Hunt, M. M., and Wharton, C. H.: New Approaches to treatment of phenylketonuria. In: P.

Table 3. Amino acid concentrations in cerebrospinal fluid (CSF) and serum of non-pku infants and in pku infants on diets with or without valine, isoleucine, and leucine (VIL)

\begin{tabular}{|c|c|c|c|c|c|c|c|c|c|c|}
\hline & \multicolumn{4}{|c|}{ PKU infants Age $12-19$ days $(n=6)$ unrestricted diet } & \multicolumn{4}{|c|}{$\begin{array}{c}\text { PKU infants Age 2-5 mo }(n=4) \text { Low phenylal- } \\
\text { anine diet }\end{array}$} & \multicolumn{2}{|c|}{$\begin{array}{l}\text { Non-PKU infants Age } \\
2 \text { wk-12 mo }(n=8)\end{array}$} \\
\hline & \multicolumn{2}{|c|}{$\mathrm{CSF}$} & \multicolumn{2}{|c|}{ Serum } & \multicolumn{2}{|c|}{$\mathrm{CSF}$} & \multicolumn{2}{|c|}{ Serum } & \multirow[t]{2}{*}{$\mathrm{CSF}$} & \multirow[t]{2}{*}{ Serum } \\
\hline & - VIL & + VIL & $-\mathrm{VIL}$ & + VIL & - VIL & $+\mathrm{VIL}$ & - VIL & + VIL & & \\
\hline Phenylalanine & $713 \pm 263$ & $431 \pm 314$ & $2180 \pm 710$ & $1689 \pm 930$ & $123 \pm 50$ & $75 \pm 27$ & $558 \pm 192$ & $434 \pm 167$ & $9 \pm 3$ & $65 \pm 23$ \\
\hline Valine & $27 \pm 2$ & $42 \pm 13$ & $209 \pm 55$ & $447 \pm 134$ & $17 \pm 5$ & $22 \pm 5$ & $222 \pm 29$ & $353 \pm 146$ & $10 \pm 3$ & $181 \pm 88$ \\
\hline Isoleucine & $10 \pm 3$ & $13 \pm 5$ & $65 \pm 18$ & $145 \pm 65$ & $4 \pm 1$ & $6 \pm 3$ & $51 \pm 7$ & $85 \pm 45$ & $3 \pm 1$ & $58 \pm 26$ \\
\hline Leucine & $20 \pm 5$ & $31 \pm 12$ & $116 \pm 33$ & $272 \pm 118$ & $11 \pm 2$ & $17 \pm 5$ & $104 \pm 31$ & $157 \pm 57$ & $11 \pm 3$ & $116 \pm 67$ \\
\hline Glycine & $9 \pm 5$ & $11 \pm 5$ & $302 \pm 108$ & $257 \pm 60$ & $7 \pm 1$ & $7 \pm 1$ & $382 \pm 18$ & $384 \pm 103$ & $7 \pm 3$ & $270 \pm 104$ \\
\hline Lysine & $21 \pm 5$ & $21 \pm 12$ & $164 \pm 60$ & $248 \pm 141$ & $20 \pm 5$ & $24 \pm 5$ & $156 \pm 50$ & $187 \pm 46$ & $18 \pm 6$ & $141 \pm 61$ \\
\hline Methionine & $5 \pm 2$ & $6 \pm 2$ & $29 \pm 8$ & $56 \pm 8$ & $4 \pm 2$ & $3 \pm 1$ & $26 \pm 13$ & $27 \pm 7$ & $4 \pm 1$ & $21 \pm 8$ \\
\hline Threonine & $34 \pm 26$ & $39 \pm 13$ & $104 \pm 53$ & $136 \pm 35$ & $39 \pm 8$ & $34 \pm 8$ & $152 \pm 28$ & $138 \pm 22$ & $35 \pm 16$ & $120 \pm 68$ \\
\hline Tyrosine & $22 \pm 6$ & $19 \pm 5$ & $66 \pm 17$ & $79 \pm 16$ & $10 \pm 4$ & $9 \pm 1$ & $42 \pm 14$ & $48 \pm 13$ & $12 \pm 5$ & $54 \pm 22$ \\
\hline Tryptophan & $1.4 \pm .4$ & $1.2 \pm .3$ & $33 \pm 13$ & $43 \pm 12$ & $1.8 \pm .5$ & $1.9 \pm .4$ & $40 \pm 10$ & $49 \pm 8$ & $1.6 \pm .5$ & $32 \pm 24$ \\
\hline
\end{tabular}

${ }^{1}$ Amino acid concentrations are expressed as $\mu$ moles/liter. 
Mittler, Ed., Research to Practice in Mental Retardation. Fourth International Congress of the IASSMD, Vol. III, Biochemical Aspects. pp. 229-239 (University Park Press, Baltimore, Md, 1977).

8. Berry, H. K., Bofinger, M. K., and Butcher, R. E.: New approach to early treatment of phenylketonuria (PKU). Soc. Neurosci. Abstr., 4: 28A (1978).

9. Berry, H. and Steiner, J. C.: Reduction of CSF phenylalanine (PA) in adult phenylketonuria (PKU) after treatment with oral branched chain amino acids. Neurology, 28: 402 (1978).

10. Berry, H. K., O'Grady, D. J., Perlmutter, L. J., and Bofinger, M. K.: Intellectual development and academic achievement of children treated early for phenylketonuria. Dev. Med. Child. Neurol., 21: 311 (1979).

11. Brunner, R. L., Vorhees, C. V., McLean, M. S., Butcher, R. E., and Berry, H. K.: Beneficial effect of isoleucine on fetal brain development in induced phenylketonuria. Brain Res., 154: 191 (1978).

12. Butcher, R. E.: Learning impairment associated with maternal phenylketonuria in rats. Nature, 226: 555 (1970)

13. Cabalska, B., Duczynska, N., Borzymowska, J., Zorska, K., Koslacz-Folga, A., Bozkowa, K.: Termination of dietary treatment in phenylketonuria. Europ. J. Pediatr., 126: 253 (1977).

14. Castells, S., Zischka, R., and Addo, N.: Alteration in composition of deoxyribonucleic acid, ribonucleic acid, proteins, and amino acids in brain of rats fed high and low phenylalanine diets. Pediatr. Res., 5: 329 (1971).

15. Hackney, I. M., Hanley, W. B., Davidson, W., and Linsao, L.: Phenylketonuria: mental development, behavior, and termination of low phenylalanine diet. J. Pediatr., 72: 646 (1968).

16. Holtzman, N. A., Welcher, D. W., and Mellits, E. D.: Termination of restricted diet in children with phenylketonuria. A randomized controlled study, N. Engl. J. Med., 293: 1121 (1975)

17. Hughes, J. V. and Johnson, T. C.: The effects of phenylalanine on amino acid metabolism and protein synthesis in brain cells in vitro. J. Neurochem., 26: 1105 (1976).

18. Hughes, J. V. and Johnson, T. C.: Hyperphenylalaninemia: effect on brain polyribosomes can be partially reversed by other amino acids. Science, 195: 402 (1977)

19. Macinnes, W. and Schlesinger, $\mathbf{K}$.: Effects of excess phenylalanine on in vitro and in vivo RNA and protein synthesis and polyribosome levels in brains of mice. Brain Res., 29: 101 (1971).
20. McKean, C. M., Boggs, D. E., and Peterson, N. A.: The influence of high phenylalanine and tyrosine on the concentration of essential amino acids in brain. J. Neurochem., I5: 235 (1968).

21. Oldendorf, W. J.: Saturation of blood brain barrier transport of amino acids in phenylketonuria. Archs. Neurol., 28: 45 (1973).

22. Prensky, A. L., Fishman, M. A., and Daftari, B.: Differential effects of hyperphenylalaninemia on the development of the brain in the rat. Brain Res., 33: 181 (1971).

23. Siegel, S.: Non-parametric statistics, (McGraw Hill, New York, 1956).

24. Snyderman, S. E., Sansaricq, C., Norton, P. M., and Castro, J. V.: Plasma and cerebrospinal fluid amino acid concentrations in phenylketonuria during the newborn period. J. Pediatr., 99: 63 (1981).

25. Swaiman, K. F., Hosfield, W. B., and Lemieux, B.: Elevated plasma phenylalanine concentration and lysine incorporation into ribosomal protein of developing brain. J. Neurochem., 15: 687 (1968).

26. Takada, G., Chow, I. Z., and Tada, K.: Maternal hyperphenylalaninemia induced experimentally: Decreased incorporation of 14-C leucine into protein in the brain of the fetus. Tohuku J. Exp. Med., 113: 173 (1974).

27. Vorhees, C. V., Butcher, R. E., and Berry, H. K.: Progress in experimental phenylketonuria. A critical review. Neurosci. Biobehav. Rev., 5: 177 (1981).

28. Walser, M. and Williamson, J. R., Eds: Metabolism and clinical implications of branched chain amino and keto acids. (Elsevier North Holland Inc., New York, 1981).

29. This protocol was reviewed and approved by the Institutional Review Board of the Cincinnati Children's Hospital Medical Center. Informed consent was obtained before valine, isoleucine, and leucine administration and specifically for two lumbar punctures.

30. We are indebted to Deede Wyatt, M.S.N. who also assisted with the studies and to Louise Wilson who performed amino acid analyses of cerebrospinal fluid and serum.

31. Requests for reprints should be addressed to: Dr. Helen K. Berry, Children's Hospital Research Foundation, Elland and Bechesda Aves., Cincinnati, OH 45229.

32. This work was supported in part by NIH Grants RR-00123 and HD05221 and by Project 427, Department of Health and Human Services, U.S.P.H.S.

33. Received for publication September 15, 1981.

34. Accepted for publication March 7, 1982. 